\title{
Micro-nano structured functional coatings deposited by liquid plasma spraying
}

\author{
Yuchun $\operatorname{HUAN}^{a}$, Kaidi $\mathrm{WU}^{a}$, Changjiu $\mathrm{LI}^{b}$, Hanlin $\mathrm{LIAO}^{c}$, \\ Marc DEBLIQUY ${ }^{d}$, Chao ZHANG ${ }^{a, *}$ \\ ${ }^{a}$ College of Mechanical Engineering, Yangzhou University, Yangzhou 225127, China \\ ${ }^{b}$ State Key Laboratory for Mechanical Behavior of Materials, Xi'an Jiaotong University, Xi'an 710049, China \\ ${ }^{c}$ ICB UMR 6303, CNRS, Université de Bourgogne Franche-Comté, UTBM, 90010 Belfort, France \\ ${ }^{d}$ Service de Science des Matériaux, Faculté Polytechnique, Université de Mons, 7000 Mons, Belgium
}

Received: March 8, 2020; Revised: June 27, 2020; Accepted: June 28, 2020

(C) The Author(s) 2020.

\begin{abstract}
Inspired by the micro-nano structure on the surface of biological materials or living organisms, micro-nano structure has been widely investigated in the field of functional coatings. Due to its large specific surface area, porosity, and dual-scale structure, it has recently attracted special attention. The typical fabrication processes of micro-nano structured coatings include sol-gel, hydrothermal synthesis, chemical vapor deposition, etc. This paper presents the main features of a recent deposition and synthesis technique, liquid plasma spraying (LPS). LPS is an important technical improvement of atmospheric plasma spraying. Compared with atmospheric plasma spraying, LPS is more suitable for preparing functional coatings with micro-nano structure. Micro-nano structured coatings are mainly classified into hierarchical-structure and binary-structure. The present study reviews the preparation technology, structural characteristics, functional properties, and potential applications of LPS coatings with a micro-nano structure. The micro-nano structured coatings obtained through tailoring the structure will present excellent performances.
\end{abstract}

Keywords: liquid plasma spraying (LPS); composite spraying; micro-nano structure; functional coatings

\section{Introduction}

Micro-nano structure is a hydrophobic functional structure existing in natural materials such as lotus leaf and gecko hair [1]. Inspired by this natural structure, bionic micro-nano structure began to appear in surface technology. Nowadays, the micro-nano structure has been widely investigated in functional surface fields

* Corresponding author.

E-mail: zhangc@yzu.edu.cn such as gas sensitive coatings, thermal barrier coatings, hydrophobic coatings, wear-resistant coatings, and photocatalytic coatings [2-6]. It offers great performance due to its advantages of high specific surface area, high porosity, and a large number of reaction sites [2,7].

Micro-nano structures mainly have two types $[8,9]$. The first is a binary-structure with both nano- and micron-particles. Two-scale particles are distributed independently of each other. As shown in Fig. 1(a), micro- $\mathrm{ZnSnO}_{3}$ cubes were decorated with nano- $\mathrm{TiO}_{2}$. The other one is a hierarchical structure in which the 


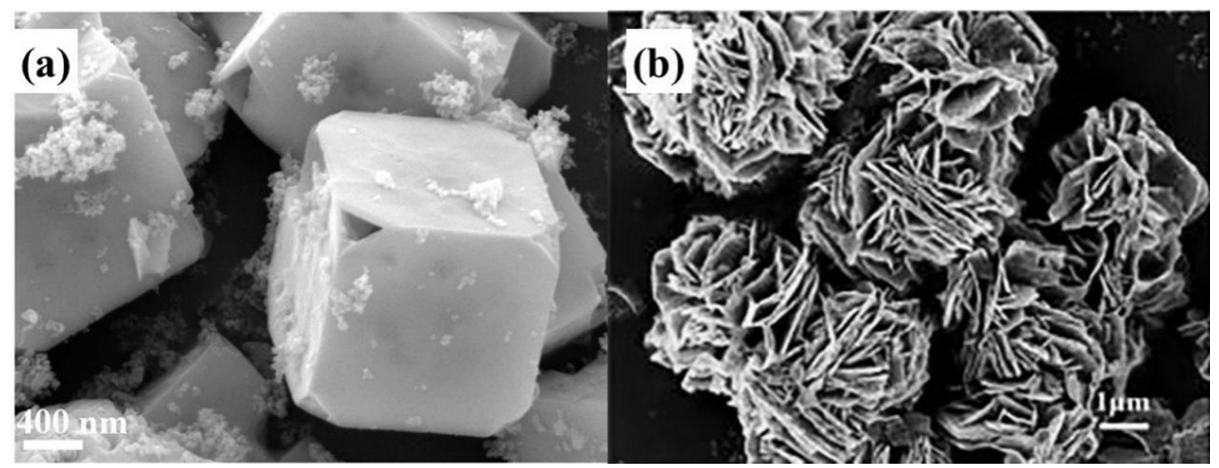

Fig. 1 Scanning electron microscopy (SEM) images of micro-nano structured materials: (a) $\mathrm{ZnSnO}_{3}$ decorated by TiO $\mathrm{T}_{2}$ and (b) flower-like $\mathrm{WO}_{3}$. Reproduced with permission from Ref. [2], C Elsevier 2019; Ref. [15], (C) Elsevier B.V. 2018.

microstructure is assembled by nano units. Figure 1(b) shows several micron-sized flower-like $\mathrm{WO}_{3}$ spheres were assembled by nanosheets. Owing to the structure combination, the material surface can show different functional characteristics. Many methods have been used to prepare micro-nano structured functional coatings, such as the sol-gel method, hydrothermal synthesis, template method, chemical deposition, etc. [10-12]. For instance, Yang et al. [13] synthesized micro-nano structured $\mathrm{ZnFe}_{2} \mathrm{O}_{4}$ hollow sphere by hydrothermal synthesis. It showed excellent glycol gas sensing performance. Movahedi and Norouzbeigi [14] prepared flower-like micro-nano structured $\mathrm{ZnO}$ coatings via a chemical bath deposition method for hydrophobic coatings. However, these methods are complicated, time-consuming, and costly. Moreover, they are not well adapted for large surfaces and they are not suitable for rapid and mass production. Besides, the complex chemical reaction process may introduce impurities, affecting the performance and service life of the coatings. Liquid plasma spraying (LPS) has a simple operation process and little effect on the substrate as well as a few impurities. At present, LPS is widely used in preparing various functional micronano structured coatings. This paper will review the principles, the preparation methods, and some major applications of the LPS method.

\section{LPS}

\section{1 Principle and classification}

Plasma spraying is one of the common methods to prepare photocatalytic coatings, wear-resistant coatings, thermal barrier coatings, etc. As for atmospheric plasma spraying (APS), spray materials are mainly metal, intermetallic, and ceramic powders. The particle diameter is usually tens of microns [16]. To obtain high-performance functional coatings with fine microstructure, nano- and submicron-particles have been used in APS [17-21]. However, in APS process, excessively fine powders may gather and block the powder feeding tube under high surface tension, which will make it difficult for the carrier gas to inject powders into the plasma jet $[22,23]$. In APS, fine powders are directly exposed to high temperatures, resulting in rapid heating and melting which destroy nanostructures [24-26]. Besides, the fine particle is too small to get enough kinetic energy to enter the plasma jet, so a higher carrier gas flow rate is required [27], which will cause severe disturbance to the plasma flame and affect the quality of the coatings [20]. To smoothly feed the fine powder particles into the plasma jet, fine particles are usually agglomerated to micron-sized particles. When such particles are injected into plasma jet and partially melted under controlled spray conditions, the coating with bimodal microstructure will be formed. The part of coating from the molten fraction presents the conventional microstructure resulting from rapid quenching of melt, while the part of unmelted fraction retains the fine structure of the original powder. In brief, APS is not suitable for coatings with a fine structure.

Compared with conventional APS, LPS has advantages in the preparation of nano- and submicron-structured coatings. Splats prepared by LPS possess a smaller size, finer structure, and higher specific surface area $[28,29]$. Therefore, LPS is suitable for the preparation of functional coatings, especially when the nanoscale structure coatings are required [30]. LPS has two types: solution precursor plasma spraying (SPPS) and suspension plasma spraying (SPS) [31,32]. The spray 
material of SPS is a suspension obtained by dispersing fine solid particles in the solvent [33]. The properties of coatings are determined by the content of solids in suspension, the substrate surface state, the solvents, and the particle properties [34]. The spray material of SPPS is a solution of metal salts. During spraying, the solution is injected into the plasma jet directly or after atomization. After a series of physical and chemical processes such as solvent evaporation, nucleation growth, heating decomposition, and particle melting, a coating will be deposited on the substrate surface [35]. Although the processes were proposed in the middle of the 1990s, SPS and SPPS are new plasma spray methods based on liquid raw materials, which can deposit ultrafine particles to obtain coatings with fine microstructures and excellent functional properties [36].

LPS can tailor the microstructure and composition of coatings. The deposited particles include sintered particles with complete/incomplete transformation, dry/ wet aggregates, and liquid droplets. After subsequent heat treatment, specific structures and compositions can be formed by crystal transition [37]. At the same time, due to the presence of the liquid, the spray materials are protected from extreme temperatures in the spray process. Although phase change is an inherent feature of plasma spraying, excessive changes will affect the performance of the coating. For instance, Zhang et al. [38] used SPS in the preparation of solid oxide fuel cells to protect cathode materials from high temperature of plasma gas. Moreover, $\mathrm{TiO}_{2}$ can be found as anatase or rutile. In photocatalyst or dyesensitized solar cells, anatase is more efficient and $\mathrm{TiO}_{2}$ should stay in this form. However, in traditional APS, the melting of $\mathrm{TiO}_{2}$ particles during flight results in a phase transition from anatase to rutile, leading to reduced efficiency. Hence, Ando et al. [39] developed low power $(1 \mathrm{~kW})$ hybrid plasma spraying (APS + SPPS) for the deposition of $\mathrm{TiO}_{2}$ coatings. The use of SPPS can avoid the direct heating of titanium dioxide particles by plasma flame and reduce the crystal transition. In another example, Cipri et al. [40] used SPS and APS combined spraying to reduce graphite loss and agglomeration via utilizing the heat-absorbing protection of liquid at high temperatures. In the experiment, graphite was successfully incorporated into the alumina coating to reduce the friction coefficient of the coating.

The process of LPS is more complex, but more operational, which can control the stoichiometric ratio, thickness, and morphology of the coating accurately [41]. Therefore, it is suitable for preparing coatings with specific microstructures.

\section{2 Hybrid plasma spraying}

Although LPS is suitable for the preparation of nanostructured coatings, the low deposition rate can be considered as a shortcoming [42,43]. Hybrid plasma spraying with liquid (suspension or solution) feedstocks and powder feedstocks can greatly improve deposition efficiency and obtain the micro-nano structure. Hybrid plasma spraying also provides a possibility of combining two-scale structures. Micro-nano structured coatings can be prepared via combining APS with LPS, which is a binary micro-nano structure to obtain improved performance. A typical schematic diagram of hybrid plasma spraying is shown in Fig. 2. The liquid and powder are injected independently. Due to the different spray materials, nanostructures and microstructures are prepared via LPS and APS, respectively.

Figure 3 shows a typical illustration of the thermal barrier coatings' formation which was deposited using ASP + SPPS [36]. In the first layer, small-size particles prepared by SPPS included molten splats (MS), spherical particles from secondary pyrolysis (SS), unpyrolyzed mass (UM), and hollow splats (HS). The molten spray-grade powder splats (MPS) with large size are formed by APS. As the spraying proceeds, the first layer gets consolidated into splats with different sizes. However, a small amount of unpyrolyzed mass after transformation (UM-T) might induce some pores within the microstructure. Finally, the coating with two scales is formed by similar stacking layers.

However, the hybrid plasma spraying is significantly different from the traditional plasma spraying and brings a lot of technical challenges, which is mainly reflected in two aspects: spray process parameters and composite spray method. Spray parameters have an important impact on coating deposition. The conventional plasma spray process is governed by some parameters such as torch, powder, spray distance, etc. Usually, even a minor change in process parameters can bring about significant changes in the properties of plasmasprayed coatings. However, the optimal spray conditions of powder and liquid are different [36]. Under the same experimental conditions, some LPS and APS process parameters are shown in Table 1. From Table 1, APS 


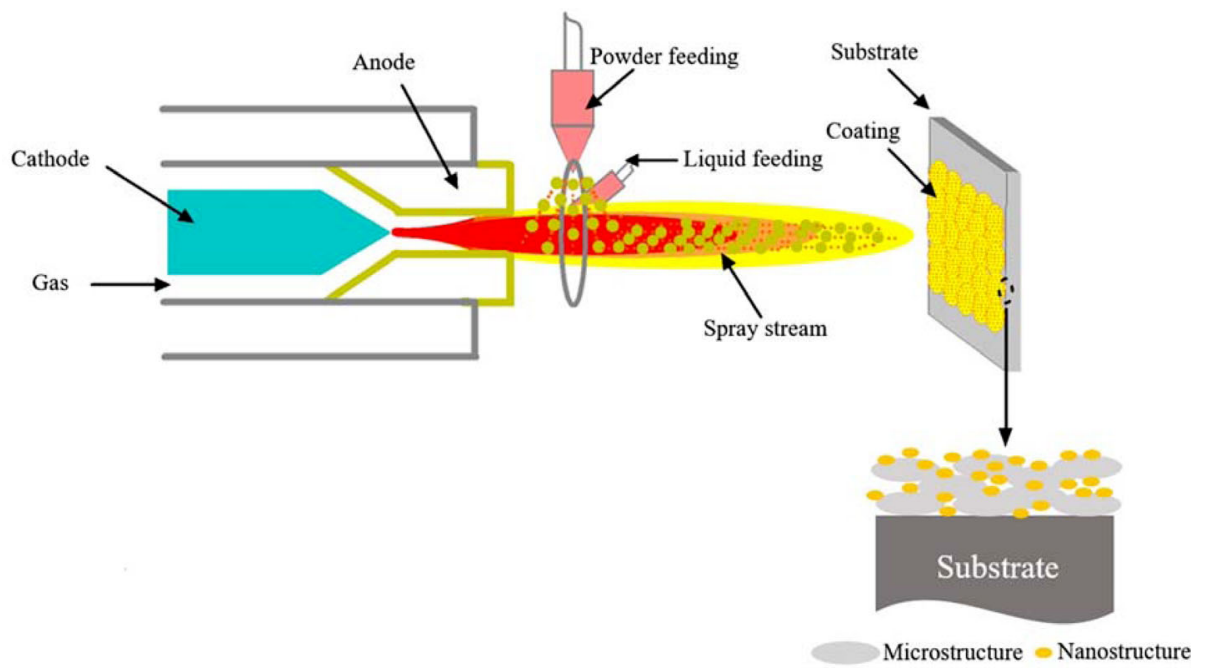

Fig. 2 Schematic diagram of hybrid plasma spraying.

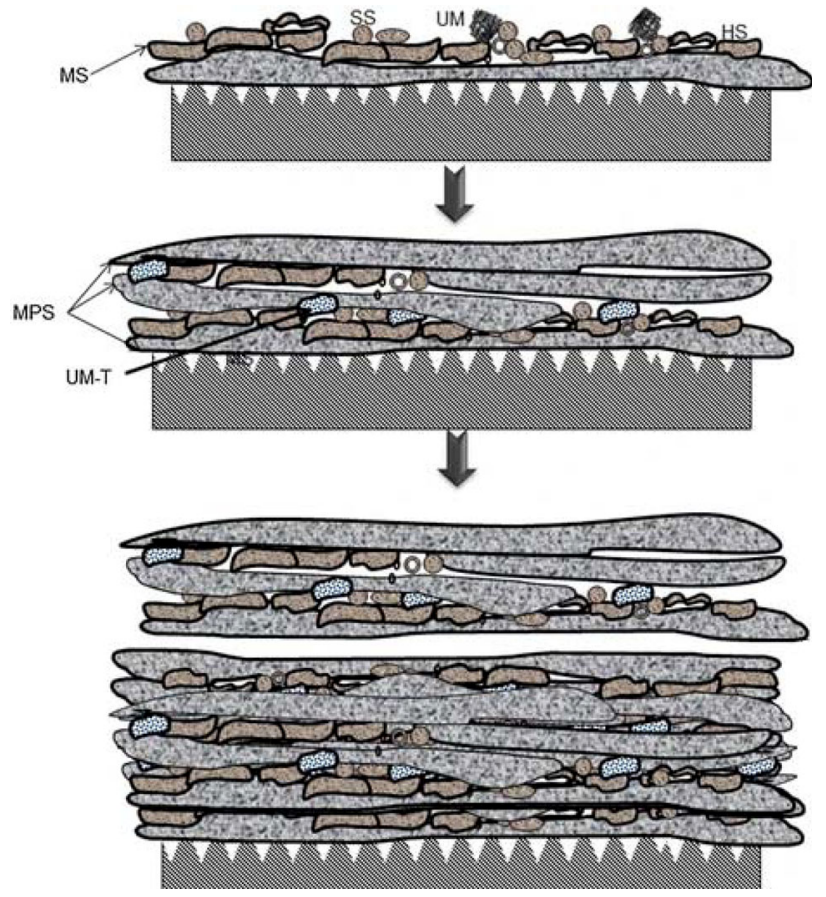

Fig. 3 Schematic diagram of the thermal barrier coatings' formation deposited via APS + SPPS. Reproduced with permission from Ref. [36], (C) Springer Nature 2015.

plasma power or current is usually lower compared with LPS, because APS plasma power which can be sufficient to deposit powder is usually not enough to convert precursor droplets into available splats in the LPS process [44]. As the evaporation of the solvent absorbs much heat, the particles produced by LPS cannot reach the ideal melting state and even the precursor reaction will be incomplete with impurities generation in relatively lower power. Regarding spray distance, LPS is usually shorter than APS. Due to a
Table 1 LPS and APS processing parameters of the same materials under the same experimental conditions

\begin{tabular}{ccccc}
\hline \multicolumn{1}{c}{ Coatings } & $\begin{array}{c}\text { Spray } \\
\text { method }\end{array}$ & $\begin{array}{c}\text { Spray } \\
\text { distance } \\
(\mathrm{mm})\end{array}$ & $\begin{array}{c}\text { Power } \\
(\mathrm{kW})\end{array}$ & $\begin{array}{c}\text { Current } \\
(\mathrm{A})\end{array}$ \\
\hline \multirow{2}{*}{ Nickel coatings [8] } & LPS & 60 & 40 & 450 \\
& APS & 80 & 40 & 500 \\
\hline $\mathrm{ZrO}_{2}$ coatings [31] & LPS & 70 & 60 & - \\
& APS & 190 & 50 & - \\
\hline $\mathrm{TiO}_{2}$ coatings [39] & LPS & 50 & 1 & 50 \\
& APS & 100 & 1 & 50 \\
\hline $\mathrm{Mo-alloy} \mathrm{coatings} \mathrm{[44]}^{2}$ & LPS & 50 & 46 & - \\
\hline $\mathrm{Yttria} \mathrm{stabilized}_{\text {zirconia (YSZ) }}$ & APS & 130 & 30 & - \\
\hline coatings [46] & LPS & 50 & - & 650 \\
$\mathrm{Al}_{2} \mathrm{O}_{3}$ coatings [47] & LPS & 65 & - & 600 \\
\hline
\end{tabular}

smaller structure, a longer spray distance will make LPS particles solidify again before impacting the substrate. However, for APS, short spray distance can give heat on the deposited particles and lead to negative effects on the coatings. Also, the parameters of the substrate temperature and feedstock feed rate can vary [45]. Therefore, the parameters of the hybrid spray process need to be optimized carefully to adapt to two different spray methods. Single splat is the basic component unit of plasma spray coatings. The splat formation on the substrate is a key factor that determines the characteristics of hybrid plasma spray coatings. As a result, to achieve the best spray process parameters, coatings' single splat or layer formation should be analyzed. Only when these coating units 
(single splat and layer) achieve the ideal structure and component, high-quality coatings can be prepared.

In terms of spray methods, Skoog et al. [48] proposed a hybrid plasma spray method with both radial feedings. Compared with axial feeding, this method can prevent the blocking of particles with sizes lower than $5 \mu \mathrm{m}$. The APS and SPPS feeding nozzles were separated on both sides of the plasma flame to realize hybrid plasma spraying with a controllable feeding rate. Although radial feeding solves the problem of powder blocking, the axial feeding can make the powder heated fully and uniformly. For further improvement, Mohanty and Moroz [49] combined radial injection (liquid feedstock) with axial injection (powder feedstock) together. The cathode outlet of the axial spray is extended to avoid the blocking caused by the deposition of molten particles on the cathode. The normal radial injection is used to inject liquid materials. In Ref. [49], another improvement method is that the axial injection nozzle of gas is located behind the anode in the spray gun. The liquid can be effectively atomized into small droplets in the spray gun, thus ensuring that all raw materials can be fully heated in the plasma flame. Spray method plays an important role in the practical application of coating preparation. Taking the coating of nickel and samaria doped ceria (SDC) for solid oxide fuel cells (SOFCs) as examples, when the coating is exposed to hydrocarbon fuel at working temperature, the nickel phase will promote the formation of solid carbon on the anode surface, resulting in performance degradation and battery damage [50]. The stability of SOFCs operating with hydrocarbons can be improved by the substitution of the nickel phase with copper [45]. However, if the mixed powder of $\mathrm{CuO}$ and SDC is directly sprayed using traditional APS to fabricate the coating, the melting temperature of $\mathrm{CuO}\left(1326{ }^{\circ} \mathrm{C}\right)$ is too low to allow it withstand high temperature required for the deposition of SDC $\left(2600{ }^{\circ} \mathrm{C}\right)$ [45,51]. Therefore, the method of combining SPS and APS (coaxial injection of materials) is adopted to solve the problem of different melting points, and LPS is used to protect copper oxide [45]. However, Cuglietta [52] found that the method of coaxial injection made coating composition inhomogeneous because of unstable powder flow in the spaying process. To avoid unstable powder flow in coaxial injection, it is necessary to select more flowable and larger-sized SDC powder and reduce velocities of the plasma jet. The spray parameters and methods of hybrid plasma spraying should be flexibly changed according to the desired coating structure and functional characteristics.

\section{Preparation and application of micro-nano structured coatings}

Typical micro-nano structured coatings obtained either by single plasma spray methods or by the combination of spray methods to modify the structure size scale are given in the following paragraphs. They are introduced separately according to the two kinds of micro-nano structures described above.

\section{1 Hierarchical micro-nano structure}

Hierarchical coatings with micro-nano structures are essentially composed of one-scale particles, and nano units build up microstructure. Thus, compared with the binary micro-nano structure, the preparation of the hierarchical micro-nano structure coatings is simple. Various coatings can be prepared using a single plasma spray method.

\subsubsection{Hydrophobic coatings}

According to the well-known "lotus effect", it is possible to create a (super) hydrophobic coating by building a two-roughness-scale structure.

$\mathrm{Xu}$ et al. [3] prepared micro-nano structured hydrophobic coatings by solution precursor vacuum plasma spraying (SPVPS). Compared with SPPS, the coating density of SPVPS is higher [42]. $\mathrm{Yb}\left(\mathrm{NO}_{3}\right)_{3}$ solution was used as SPVPS raw material to deposit layered $\mathrm{Yb}_{2} \mathrm{O}_{3}$ coating. As shown in Fig. 4, the coating was characterized as the spherical micron-clusters composed of nanoparticles. On the surface of the clusters, fine nanoparticles and nanosplats can be observed. This dual-scale and hierarchical structure provided a superhydrophobicity. The forming of the micro-nano structure can be explained as follows: as the plasma jet with particles runs into the substrate, the flow is divided and then particles move in parallel along the top of the substrate. Next, fine nanoparticles impact the substrate and move following the flow because of their small inertia. Finally, the particles impinge on the surface protrusion created by grit blasting, generating the clusters. The coating became hydrophilic after high-temperature treatment and 
regained superhydrophobicity by vacuum treatment. This process offers potential in the mass production of superhydrophobic coatings. In addition, the antifouling and drag reduction characteristics of hydrophobic coatings make them widely used in marine vehicles [53,54]. By suspension flame spraying, Zhai et al. [55] deposited perfluoroalkoxy (PFA)/nano-silver (Ag) hydrophobic coatings on aluminum substrates using $\mathrm{PFA} / \mathrm{AgNO}_{3}$ suspension. With the addition of $\mathrm{Ag}$ nanoparticles, the surface roughness of the coating increased greatly and a micro-nano structure was formed. The hydrophobic coatings showed remarkably strengthened antifouling and drag reduction performance. Sharifi et al. [56] compared the hydrophobic $\mathrm{TiO}_{2}$ coatings prepared by SPS using ethanol-based suspension and water-based suspension. The coating wettability is significantly influenced by the geometrical micro- or nano-roughness of the surface [57]. Due to the presence of larger aggregates of particles in ethanol-based suspension, the dual-scale hierarchical roughness was prepared and the coating showed better water repellency. So for hydrophobic coatings, the dual-scale hierarchical roughness (micro-nano structure) improves the performance. To form this structure, the surface roughness and liquid materials are two important factors.

\subsubsection{Gas-sensitive coatings}

Semiconductor gas-sensitive coatings based on metal oxides are becoming one of the most attractive sensing technologies. These sensors are based on the following principle: a semiconducting sensitive coating deposited on an insulating substrate fitted with a pair of electrodes (most of the time-interdigitated electrodes) has an electrical conductivity that depends on the concentration of a target gas in the ambient atmosphere. This phenomenon is due to the reversible adsorption of the gas molecules on the surface of the semiconductor.
If the interaction between the gas and the sensitive material is strong enough, the electron exchanges would be modified and then change the concentration of charge carriers and, as a consequence, lead to a change in conductivity.

The microstructures of gas-sensitive coatings have a big impact on their sensitivity and selectivity. Gas sensors need small-scale and porous structures to provide high specific surface area and gas flow channels to favor the contact with the gas. Secondly, the charge carrier concentration is mainly affected by Debye length on the surface of the semiconductor to a certain extent. According to the gas sensing theory, if the grain size in gas sensing coating is less than two times of the Debye length, the gas sensing layer will possess high sensitivity and fast response ability [58]. That is why a micro-nano structure is a good choice. Huang et al. [9] prepared $\mathrm{WO}_{3}$ gas-sensitive coatings with a micronano structure for ozone by liquid precursor flame spraying similar to LPS. The coating presented a typical porous structure and micron-clusters were built up by nanoparticles. To form this structure, ethanol content, solute concentration, and spray distance are important factors. As shown in Figs. 5(a) and 5(b), the coating possessed micro-nano structures with large specific surface area and high porosity which increased reaction sites and greatly improved the sensing performance. You et al. [59] prepared $\mathrm{ZnFe}_{2} \mathrm{O}_{4}$ coatings by SPS for low concentration acetone detection. Micronagglomerates assembled by $\mathrm{ZnFe}_{2} \mathrm{O}_{4}$ nanoparticles finally formed the coating porous structure. Arc current was optimized to retain as many nanoparticles as possible. The excessive current could agglomerate over-melted nanoparticles to form large particles, which negatively affected gas sensing properties. At $200{ }^{\circ} \mathrm{C}$, the gas sensor displayed extremely short response/recovery time and fine selectivity to acetone.
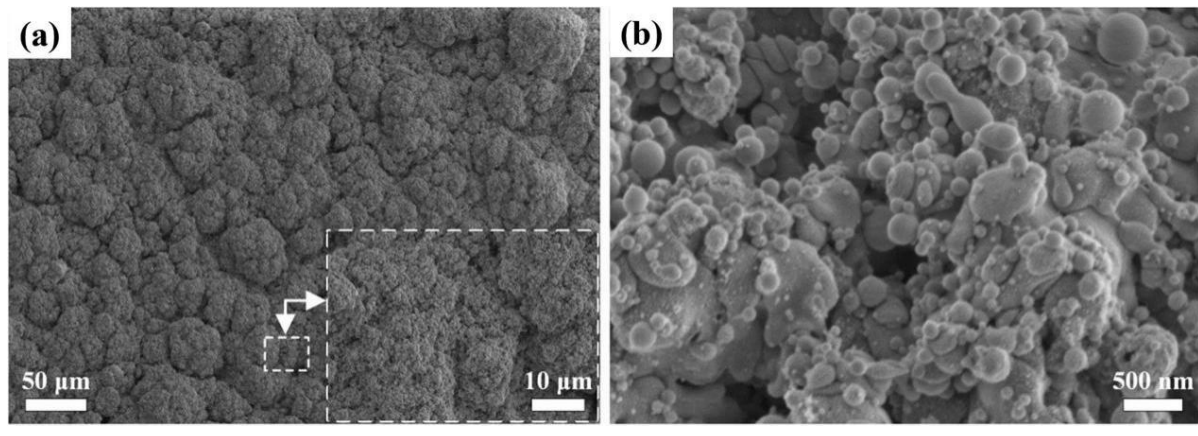

Fig. 4 SEM images of $\mathrm{Yb}_{2} \mathrm{O}_{3}$ coating: (a) surface and (b) surface in high magnification. Reproduced with permission from Ref. [3], (C) Elsevier Ltd. 2018. 
Zinc-oxide based materials are excellent $\mathrm{NO}_{2}$ gas sensing materials [60]. Geng et al. [61] prepared gassensitive $\mathrm{CdS}-\mathrm{ZnO}_{1-x}$ coatings with similar micro-nano structures by SPPS. Composite $\mathrm{CdS}-\mathrm{ZnO}$ coatings were prepared via spraying $\mathrm{Zn}\left(\mathrm{CH}_{3} \mathrm{COO}\right)_{2}$ and $\mathrm{CdS}$ solution. To achieve the oxygen-vacant $\mathrm{CdS}-\mathrm{ZnO}_{1-x}$ coatings, a further process with $\mathrm{H}_{2} \mathrm{O}_{2}$ treatment and annealing was applied. The sensors showed an excellent response to $\mathrm{NO}_{2}$. For the preparation of gas-sensitive coatings, the LPS current should be relatively low. In this way, the particles can be partially melted in the spray process to form the porous structure required by the gas-sensitive coatings. At low arc current, the tiny size of particles is retained and the agglomeration of over melted particles is avoided.

\subsubsection{Biomedical coatings}

In the biomedical coating field, hydroxyapatite (HA) has been applied for about 50 years. Initially, it was only used for congenital bone defects and traumainduced cavities. Nowadays, HA coating has become the main force of modern biomedical implants because of its properties [62]. HA can promote bone growth and is converted to bone and the incorporation of copper ions could improve the mechanical properties of coatings and the antibacterial capability for biomedical application [63,64]. Using the SPPS process, complex powder preparation steps can be avoided and morphology of the coatings can be controlled [21]. Unabia et al. [20] prepared copperdoped HA coatings using SPPS. The spray liquid is calcium-phosphate solution doped with copper ions. The coating microstructure showed agglomerated and spherical nanoparticles on the surface. Titanium dioxide is also widely applied in biomedicine as an implant material due to good biocompatibility and chemical stability $[65,66]$. The unique structure of titanium dioxide coating can be prepared by adjusting spray parameters [67]. On the plasma-sprayed $\mathrm{TiO}_{2}$ coating, the rough surface is not only conducive to the connection and differentiation of osteoblasts in vitro, but also promotes the growth of bone tissue to improve the bonding between implant and bone. Zhang et al. [68] used nano-anatase suspension as raw material to prepare hierarchical $\mathrm{TiO}_{2}$ coatings with a micro-nano structure by induction suspension plasma spraying (ISPS). The porous coating was mainly composed of nanoparticles and micron-clusters. Considering the experimental result, the liquid feed rate was the main factor affecting the morphology and anatase content of the coating. Due to the micro-nano structure, $\mathrm{TiO}_{2}$ coating cell adhesion and proliferation were increased significantly compared with a smooth surface.

\subsubsection{Photocatalytic coatings}

In the field of photocatalysis materials, the micro-nano structure receives increasing attention for its larger specific surface area and higher photocatalytic activity $[69,70]$. Compared with the traditional preparation method of photocatalytic coatings, LPS is more and more popular due to practicability and flexibility. Toma et al. [71] compared the $\mathrm{TiO}_{2}$ coatings prepared via SPS and APS. SPS coating micromorphology consisted of fine particles as well as large agglomeration with micro-nano structures. The photocatalytic test results showed that the SPS coatings presented a better photocatalytic efficiency to the decomposition of $\mathrm{NO}_{x}$ pollutants than APS coatings due to the SPS protection on the original anatase phase and a finer grain size. $\mathrm{Yu}$ et al. [72] prepared micro-nano structured $\mathrm{ZnO}$ rod
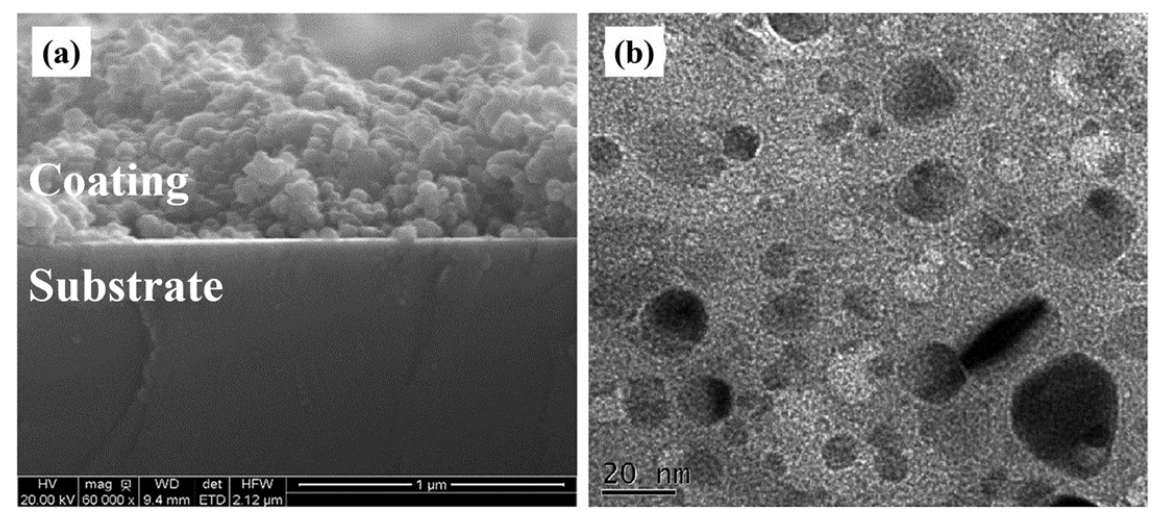

Fig. 5 (a) SEM image of the cross-sectional microstructure of $\mathrm{WO}_{3}$ coating and (b) transmission electron microscopy (TEM) image of the spherical nanosized $\mathrm{WO}_{3}$ grains. Reproduced with permission from Ref. [9], (C) Elsevier B.V. 2017. 
coating using SPPS. The coatings allow the complete photodegradation of the Orange II dye under UV light irradiation within $2 \mathrm{~h}$. The results showed that the microstructure of $\mathrm{ZnO}$ can be easily controlled by adjusting the composition of the solution precursor. In addition to spray liquid raw materials, other spray process parameters also have important impacts. Zhai et al. [73] fabricated black titanium dioxide coatings with a porous micro-nano structure and high photocatalytic activity. To reach the desired titania coatings, plasma spray power and gun moving speed were optimized. Under higher spray power, large pores can be observed from the micromorphology of the black coating which had lager specific surface areas than normal white coatings. Moreover, a higher temperature spray process causes partial phase structure transformations of $\mathrm{TiO}_{2}$. The exceptional structure of black coating enhanced photocatalytic activity. Therefore, micromorphology and composition of photocatalytic coatings can be effectively changed by adjusting the spray process parameters, and thus photocatalytic performance is improved.

Compared with other coating preparation technologies, LPS is a straightforward process. In general, hierarchical coatings prepared using LPS improve the surface properties of functional coatings. Single liquid plasma spraying can be applied to fabricate hierarchical micronano structured coatings assembled by nanoparticles directly. However, for binary micro-nano structured coatings, the co-deposition method is needed.

\section{2 Binary micro-nano structure}

Binary micro-nano structured coatings have both nanoand micron-particles at the same time, which cannot be achieved by a single spray method. Therefore, the preparation of binary micro-nano structured coatings uses the combination of APS and LPS. Micronparticles are deposited via APS and nanoparticles are deposited using LPS. Compared with single spray methods, the hybrid spraying can better tailor the micro-nano structure and the prepared coatings usually have the advantages of two spray processes.

Binary micro-nano structure coatings have three types: layered coatings, composite coatings, and graded coatings (Fig. 6). Layered coatings are prepared via alternate deposition in which micron-structures and nano-structures will be combined layer by layer. Two different scales of structures are relatively separate and the layer of different structures can be observed by cross-sectional images. This kind of structure can be simple two upper and lower layers or multi-layered. Composite coatings are prepared by feeding two different materials at the same time. This method combines fine nano-sized features with rough layered features in micron-size. Dispersed nanoparticles adhere to the surface of the micron-structure. The preparation of graded coatings is similar to the composite coatings. When feeding two materials at the same time, adjusting the feeding rate of one or two raw materials can realize the gradual change of coating structure from bottom to top. As shown in Fig. 6, the bottom was dominated by micron-structures, and the top was dominated by nanostructures [43]. At present, few examples prepared graded coatings by composite spraying, but there are similar researches. Wang et al. [74] applied SPS to produce functionally graded $\mathrm{La}_{2} \mathrm{Zr}_{2} \mathrm{O}_{7} / 8 \mathrm{YSZ}$ thermal barrier coatings by controlling the two different suspension feeding rates.

The functional micro-nano structure coating in this paper mainly refers to the part of coatings which is prepared by two different spray methods and plays the
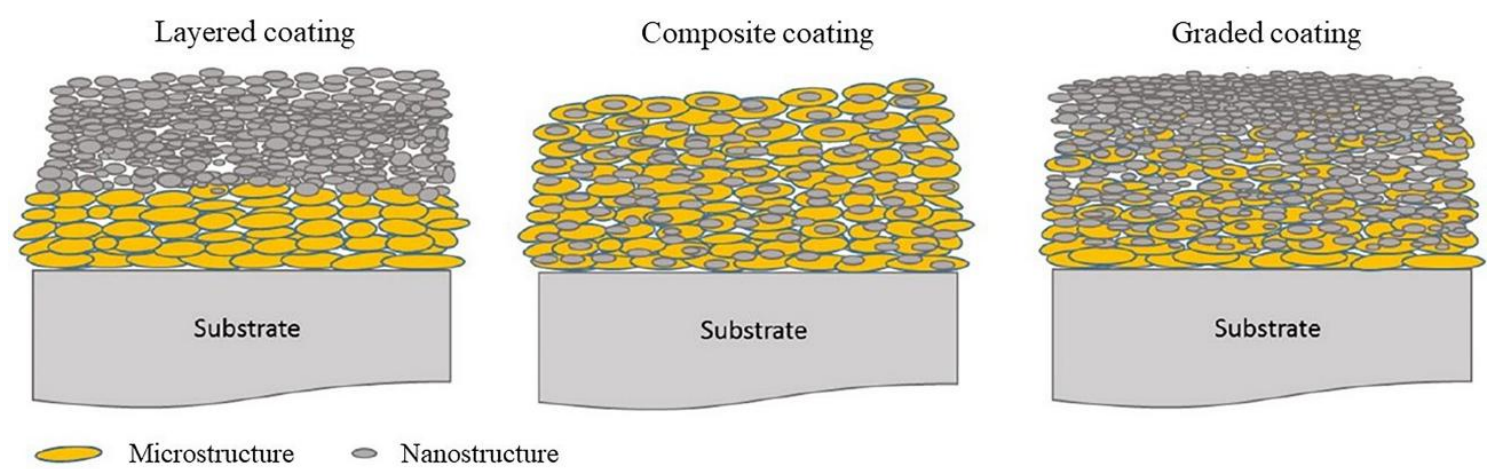

Fig. 6 Schematic diagram of three structures of binary micro-nano structured coatings. Reproduced with permission from Ref. [43], (c) Elsevier Ltd. 2018. 
main function, such as gas sensor, thermal barrier, etc.

\subsubsection{Electrode coatings for hydrogen production}

The demand for new clean energy is raised due to growing environmental pollution and the rapid depletion of fossil fuels [75]. Hydrogen is a typical clean energy source, and advanced electrode coating with high performance is a promising material to reduce the cost and energy consumption of water electrolysis in hydrogen production. Among different surface modification technologies, plasma spraying has shown its good performance of electrode coating production as a cost-effective process, such as APS and SPS [76,77]. Although the performance of SPS coating is better with high surface roughness and specific surface area, a hydrogen bubble blockage problem exists because of too small pores in the coating. To solve the problem, Aghasibeig et al. [8] used APS + SPS composite spraying to fabricate a dual-scale structure coating. The spray materials were micron-Ni powders and ethanol suspension with $\mathrm{NiO}$ nanoparticles. APS coating was deposited first, and then multi-layered SPS coatings were deposited above it. This hybrid spraying was divided into two separate steps: APS and SPS. Therefore, the study did not need to consider the spray process parameters of APS and SPS co-spraying. Finally, a typical layered structure coating was obtained by reduction treatment. It showed that the nano-aggregates were added on the rough and porous micron-structure. The micron-sized features promote the escape of gas bubbles and the contact between the electrolyte and coating surface, and the nano-sized features improved the specific surface area of the coating. Thus, the electrocatalytic activity of the electrode was improved. The same group [78] further prepared three-dimensional (3D) electrode coatings for hydrogen production with fin arrays micro-nano structure using APS + SPS. To form the structure of the array, the substrate was masked by wire mesh in the APS process. Then, SPS was used to add nanostructures on the APS layer. Different meshes were used for experimental comparison. The fins in the coarse mesh screen showed a trapezoidal shape, whereas domeshaped fins in the fine mesh screen. The electrode prepared by a fine mesh screen had a larger surface area, which improved the activity of the electrode again. The cross-sectional and 3D surface images of the fin array micro-nano structured coating are shown in Fig. 7. Experimental results showed that the electrode activity was mainly determined by surface roughness.

\subsubsection{Thermal barrier coatings}

As for thermal barrier coatings (TBCs), they can also be prepared via combining APS and SPS. Introducing considerable porosity is a common method to improve the insulation performance of TBCs [79]. Many conventional methods were applied to introducing pores, such as replica, sacrificial template, and direct foaming technique $[80,81]$. Although a large number of pores can be formed, these methods introduce impurities and the process is difficult in comparison with thermal spraying. Most importantly, TBCs cannot effectively utilize these internal pores to improve thermal barrier performance, because the thermal conductivity of the material is closely related to the pore size and geometry of the coating [82]. Zhang et al. [4] prepared layered YSZ by APS + SPS, in which homogeneous nanoparticle heaps with a large aspect ratio were introduced by SPS to replace large-scale pores. It solved the problem of a low ratio of effective

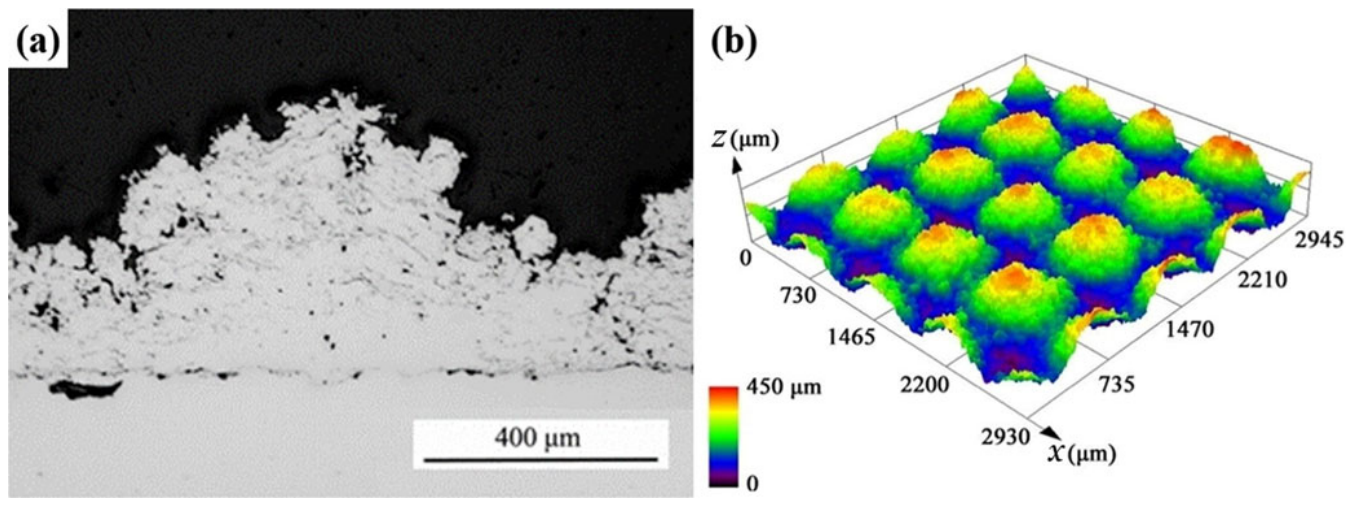

Fig. 7 (a) SEM image of coating cross-sectional surface and (b) confocal laser scanning microscope (CLSM) image of electrode 3D top surface topography. Reproduced with permission from Ref. [78], (c) Elsevier B.V. 2016. 
thermal barrier pore. High aspect ratio heaps enhanced the thermal barrier performance of YSZ coating. However, in the process of hybrid plasma spraying, the introduction of nanoparticle heaps with a large aspect ratio is a challenge. Because when the suspension droplet impacts on the substrate, the solvent should not be completely evaporated to ensure that the suspension droplet has enough fluidity to spread. At the same time, the residual amount of solvent must be controlled. Through the experiment of single nanoparticle heap formation, the long spray distance was determined and the organic solvent was replaced by water. This method can not only obtain ideal nanoparticle heap structure, but also avoid the overlapping of them. As shown in Fig. 8, the thermal barrier coatings showed obvious layered characteristics. The coating prepared by APS + SPPS was a bimodal micron-structure consisting of both dense and loose regions, and the nanoparticle heaps were sandwiched between layered micronstructures. Compared with conventional powder spray coatings, the thermal conductivity of composite coatings was reduced by $1 / 5$.

The micro-nano structure improves not only the thermal barrier properties of the coating, but also the service life [83]. Indeed, the YSZ TBCs prepared by APS have been widely used due to the internal porous structure and micro-cracks in coatings which ensure the barrier of heat transfer. However, this kind of coatings tends to sinter during service, which will make coatings peel off and fail [84]. The structure of APS coating was porous and lamellar whereas SPPS coating was vertical cracks structure $[46,85]$. It is well known that the coatings with vertical cracks can increase thermal cycling durability of TBCs by offering enhanced strain tolerance, and nanostructure can exert better thermal shock resistance and lower thermal conductivity [32]. The advantages of the two kinds of coatings can be combined with composite spraying. Joshi et al. [83] prepared YSZ TBCs with a micro-nano structure by combining APS with SPPS. Different kinds of coatings with micro-nano structures were prepared by feeding mixed powder and liquid at the same time or consecutive feeding in turn: covering the APS layer by the SPPS layer. These two structures were the layered coating and composite coating mentioned above.

In this process, two kinds of raw materials are separately fed axially to control their feed rates and injection angles. By the investigation of particles collected in flight, high plasma power and appropriate precursor flow rate were found to help obtain welldefined spherical particles. Then, in the studies of splat
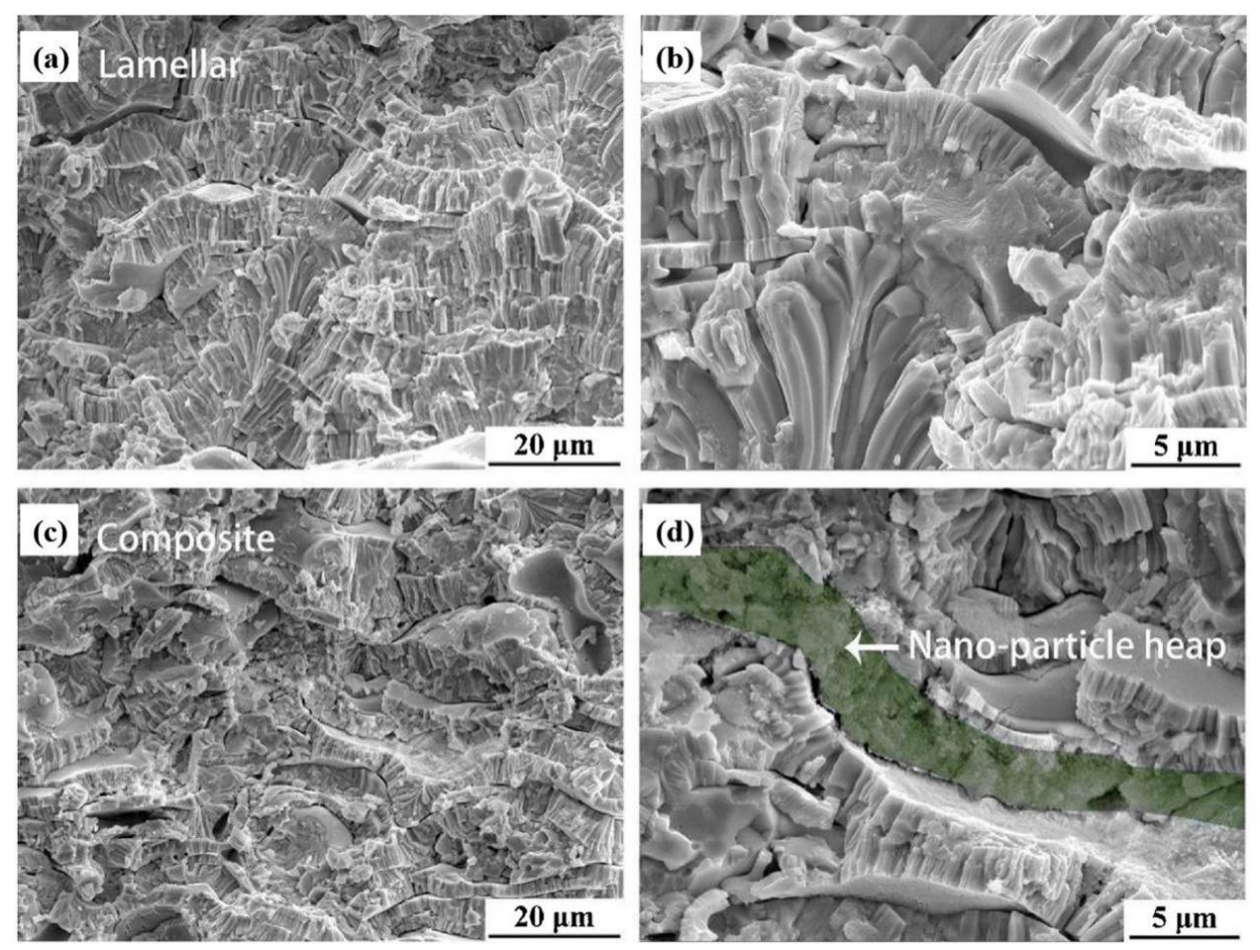

Fig. 8 SEM image of cross-sectional surface: ( $a, b)$ APS and (c, d) SPS + APS. Reproduced with permission from Ref. [4], (C) Elsevier Ltd on behalf of The editorial office of Journal of Materials Science \& Technology 2017. 
formation using hybrid spraying, process parameters closer to those favoring the LPS appear more promising to form composite micro-nano structures. Fine-sized solution-based splats can be deposited over larger splats originating from the spray-grade powder, as desired in the case of composite coatings. The shapes of splats from the powder and the solution precursor were close to disk-shaped form, which are preferred for better adhesion-cohesion within the micro-nano structures. In terms of performance, their thermal cycling durability was much better than that of APS coatings. In layered coatings, the top SPPS porous nanostructure coatings retained vertical cracks which were protective as well as the bottom APS coatings retained larger pores and obtained lower thermal conductivity. So the micro-nano structure prepared by alternate deposition had better thermal barrier performance and durability and it had the advantages of both SPPS and SPS coatings.

High-temperature corrosion is another important factor affecting coating life [86]. Ajay et al. [46] compared the thermal corrosion resistance of YSZ TBCs prepared by APS and SPPS, respectively. In an environment of hot corrosive salts, the vertical crack of SPPS coating would become a channel to transport salt to the interface between the bonding layer and the insulation layer and accelerate the failure of the coating. Sivakumar et al. [87] studied the thermal corrosion behavior of powder-solution plasma-sprayed YSZ TBCs (composite micro-nano structure) in chloride ion and vanadate environment. As shown in Fig. 9, the thermal barrier performance and thermal corrosion resistance of composite TBCs were much better than those of SPPS or SPS TBCs. Besides the absence of vertical crack, a composite micro-nano structure could reduce the induced stresses within the upper coatings and avoid densification under high temperatures $[88,89]$. Therefore, micro-nano structured coatings have their advantages. Besides, some researchers have studied new materials to solve the hot corrosion problem. $\mathrm{La}_{2} \mathrm{Ce}_{2} \mathrm{O}_{7}$ (LC) is reported to have extremely low thermal conductivity and can prevent the infiltration of hot corrosive salts by the formation of the apatite phase [90]. Praveen et al. [91] prepared doublelayered TBCs containing YSZ and $\left(\mathrm{La}_{0.9} \mathrm{Gd}_{0.1}\right)_{2} \mathrm{Ce}_{2} \mathrm{O}_{7}$ (Gd-LC) by combing SPPS and APS. For SPPS based Gd-LC layer, nitrate solutions of $\mathrm{La}, \mathrm{Gd}$, and Ce were prepared as spray material, and YSZ powder for SPS/YSZ coating was deposited first followed by SPPS Gd-LC. APS coatings exhibited lamellar features and SPPS showed coating nano-sized structure with small pores. In the same hot corrosion environment, the micro-nano structured TBCs had better thermal cycling durability than standard YSZ coatings.
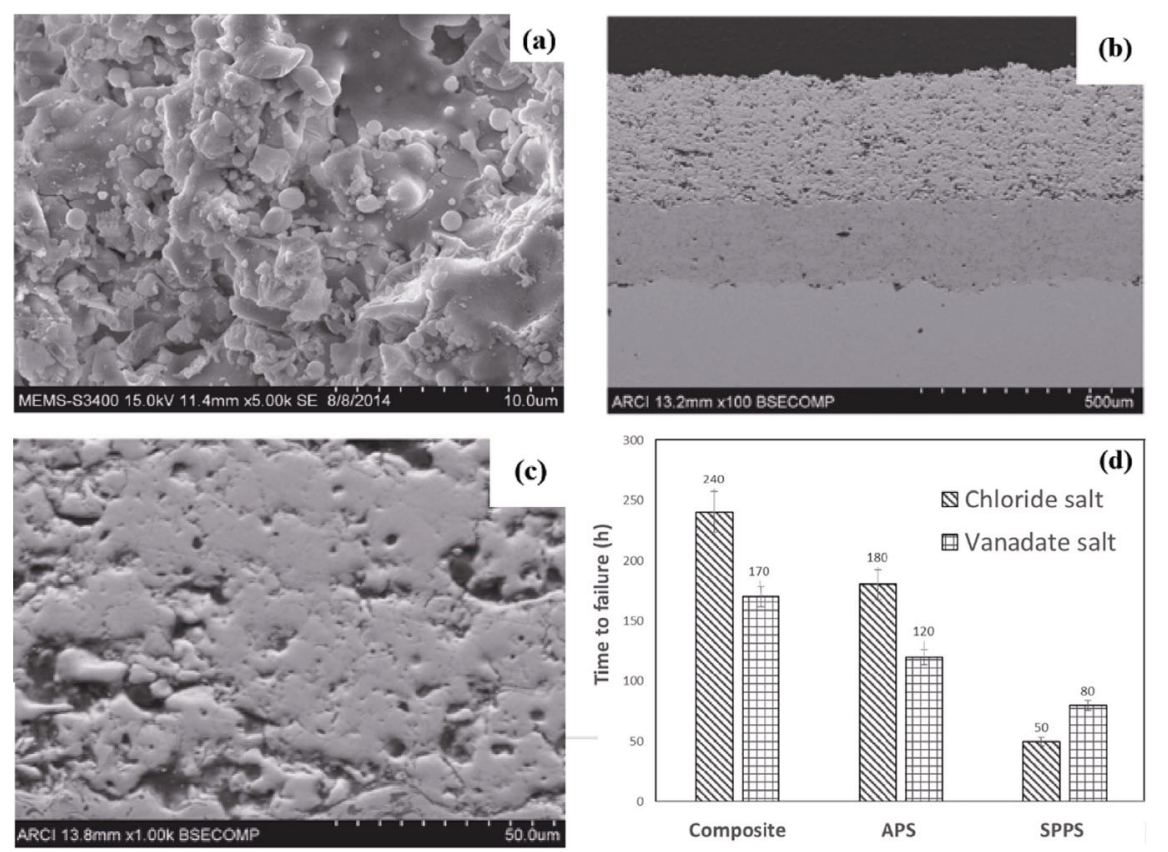

Fig. 9 SEM image of (a) surface morphology, (b) cross-sectional image (at low magnification), and (c) cross-sectional image (at high magnification) of composite YSZ TBCs; (d) time for the failure of three kinds of YSZ coatings after hot corrosion testing in chloride and vanadate environments. Reproduced with permission from Ref. [87], (c) Elsevier B.V. 2018. 
Some reports studied on the co-spraying of SPPS and SPS to prepare TBCs. Hou et al. [92] prepared $\mathrm{Ba}\left(\mathrm{Mg}_{1 / 3} \mathrm{Ta}_{2 / 3}\right) \mathrm{O}_{3}(\mathrm{BMT})$ thermal barrier coatings via SPPS and SPS. $\mathrm{Ta}_{2} \mathrm{O}_{5}$ nanoparticle suspension was used for SPS, and barium and magnesium nitrate solution was used for SPPS. Due to an excessive sintering temperature of BMT [93], which would cause the evaporation and loss of $\mathrm{Mg}$, this method could reduce the loss of magnesium element under the plasma flame and ensure the purity of coating without complex secondary phases. The effects of power and spray distance on coating deposition were studied to determine the optimum process parameters. The existing research on the co-spraying of SPPS and SPS is relatively rare. However, the SPPS + SPS provides more possibilities for designing and tailoring of micronano structures.

\subsubsection{Wear-resistant coatings}

To improve the performance of wear-resistant coatings, the addition of high-temperature stable hard particles with nano- or micron-size to common wear-resistant matrix has also attracted much attention. Many traditional methods are trying to form this dispersed phase in the matrix, such as powder metallurgy, in-situ synthesis, casting technology, electrodeposition, and traditional thermal spraying, but these methods are not easy to adjust according to the demand [94]. Generally, the traditional thermal spray method uses a given mixing ratio of powder material, which limits the flexibility of design and production. Besides, as mentioned above, APS has difficulty in spraying nanopowder. An et al. [95] modified nano- $\mathrm{Al}_{2} \mathrm{O}_{3}$ powder with $\mathrm{KH}-560$ silane coupling agent to improve its dispersion. Then the nano- and micron- $\mathrm{Al}_{2} \mathrm{O}_{3}$ powders were uniformly mixed by ultrasonic waves so that all the nanoparticles were attached to the micronparticles. This process avoided the blockage problem of nanoparticles in traditional APS. The resistance performance to brittle fracture and wear resistance of the coatings is strengthened significantly with an increasing amount of the nanopowder. This method mainly focused on the improvement of raw materials, but how to retain nano-structures after plasma spraying needs further study. Adding hard nanoparticle by composite plasma spraying can improve wear resistance of the coating. Lohia et al. [44] mixed zirconium acetate and yttrium nitrate hexahydrate salt as a solution precursor material and Mo-alloy blend powder as APS material to prepare wear-resistant coatings with micronano structure by composite spraying. The SPPS coating was mainly composed of YSZ spherical particles with nano- or submicron-size, which improved wear resistance of the coating. The wear rate was reduced by about $40 \%$ under the lubrication condition and about $20 \%$ under dry grinding conditions. Similarly, Murray et al. [47] prepared $\mathrm{Al}_{2} \mathrm{O}_{3}-\mathrm{YSZ}$ coatings using SPS and APS. The $\mathrm{Al}_{2} \mathrm{O}_{3}$ powder and $\mathrm{YSZ}$ suspension were injected axially at the same time. In a comparison of $\mathrm{Al}_{2} \mathrm{O}_{3}$ coatings, the hybrid $\mathrm{Al}_{2} \mathrm{O}_{3}-\mathrm{YSZ}$ coatings had significantly lower porosity, higher fracture toughness, and wear resistance. Compared with gas-sensitive or thermal barrier coatings, wear-resistant coatings need higher density. Therefore, the hybrid plasma spray process of wear-resistant coating often uses higher spray power and shorter spray distance. By splat formation studies, higher spray power enables the pyrolysis of the liquid precursors to form in-situ particles and ensures good splat formation during their subsequent melting process. At a higher spray distance, finer particles formed from the solution precursor re-solidify, and the nanostructure would be destroyed. Therefore, it is necessary to reduce the spray distance appropriately to avoid the powder particles from incomplete melting.

Other researchers added alumina nanoparticles into the wear-resistant coating matrix via liquid spraying. Bolelli et al. [96] introduced submicron $\mathrm{Al}_{2} \mathrm{O}_{3}$ particles into the NiCrAlY matrix by APS + SPS, which was characterized as a dual-scale structure of large NiCrAlY lamellae interspersed with fine and rounded $\mathrm{Al}_{2} \mathrm{O}_{3}$ particles. Bolelli et al. [97] also added h-BN based on $\mathrm{NiCrAlY}+\mathrm{Al}_{2} \mathrm{O}_{3}$ composite coatings by hybrid plasma spraying to achieve ternary systems. Particularly, the incorporation of lubricants within coatings is hot research in the field of wear-resistant coatings [98]. This ternary system contained both hard phase and solid lubricants to obtain high wear resistance. The submicron $\mathrm{Al}_{2} \mathrm{O}_{3}$ and h-BN particles tended to agglomerate together in the coating. In a dual-scale structure, $\mathrm{Al}_{2} \mathrm{O}_{3}$ and h-BN submicron particles tended to cluster. The sliding wear resistance of the coating was further enhanced by the addition of h-BN. Obviously, this method of composite spraying is not limited to plasma spraying. Mohanty et al. [94] used arc spraying and supersonic flame spraying (solution of precursors material) to insert $\mathrm{SiO}_{2}$ and $\mathrm{Al}_{2} \mathrm{O}_{3}$ nanoparticles into nickel-chromium alloy matrix 
to improve the creep resistance and thermal fatigue resistance of the coating. Kiilakoski et al. [99] fabricated $\mathrm{Al}_{2} \mathrm{O}_{3}-\mathrm{YSZ} / \mathrm{ZrO}_{2}$ wear-resistant coating with micro-nano structure by high-velocity oxygenfuel spray to improve mechanical properties. The solution precursor and powder were coaxial feeded, and $\mathrm{YSZ} / \mathrm{ZrO}_{2}$ nanoparticles produced by solution precursors were sandwiched between micron- $\mathrm{Al}_{2} \mathrm{O}_{3}$ lamellae in coatings. The added nanostructured phase could bring out the toughening effect. However, the mechanical strength of the coatings was not optimal due to the excessive amount of the nanostructured $\mathrm{YSZ} / \mathrm{ZrO}_{2}$ addition. Therefore, the process needs to be further improved.

\subsubsection{Gas-sensitive coatings}

Binary micro-nano structures can improve gassensitive properties in different aspects. $\mathrm{ZnO}$ is an excellent choice for hydrogen sensing materials [100]. However, pristine $\mathrm{ZnO}$ shows a low selectivity to hydrogen gas [101]. Hoppe et al. [102] reported that the hydrogen response and selectivity of $\mathrm{ZnAl}_{2} \mathrm{O}_{4^{-}}$ decorated $\mathrm{ZnO}$ with binary micro-nano structure were greatly improved. The $\mathrm{ZnAl}_{2} \mathrm{O}_{4}$ nano-crystallites distributed on top of $\mathrm{ZnO}$ micron-wires densely. However, the smaller the grain size, the higher the specific surface area and the more reaction sites [103]. As a result, the grain size of the gas-sensitive layer is generally at the nanoscale [104], such as nanospheres, nanowires, nanobelts [105-107], etc. However, the smaller the grain size, the lower the critical temperature of grain growth, and the working temperature of sensors can usually reach $200-600{ }^{\circ} \mathrm{C}$ [108]. At elevated temperatures, the nanograins grow up, which will reduce the sensitivity. Hence, the thermal stability of nanomaterials needs to be solved urgently. Previous studies showed that the thermal stability of $\mathrm{WO}_{3}$ coatings with a micro-nano structure prepared by APS + SPPS had been greatly improved compared with that of SPPS coatings [109]. $\mathrm{WO}_{3}$ micrometer particles were used as powder material and ammonium tungstate hydrate dissolved in deionized water was used as liquid precursor material. The nozzle angles (from torch axis) of SPPS and APS were set to $75^{\circ}$ and $90^{\circ}$, respectively. By comparing the effects of different spray powers, lower power is beneficial to get fine particles by SPPS and porous structure by APS. Since the liquid and powder were fed at the same time, the gas-sensing coating was a composite micro-nano structure. As shown in Fig. 10, nanoparticles were distributed independently on the surface of micronstructures, avoiding physical contact of nanoparticles. Therefore, nanoparticles would not move, agglomerate, or grow, thus effectively improving the thermal stability at working temperature.

In addition to improving thermal stability by modifying the composition or structure, the combination of different metal oxides can also lower the working temperature to avoid agglomeration of the particles. $\mathrm{ZnSnO}_{3}$ particles are often used in ethanol gas sensors, but the sensors also need to work at high temperatures to obtain sufficient gas sensing properties [110,111]. Except for the problem of thermal stability, the hidden danger of detecting flammable and explosive gases at high temperatures should not be neglected. Nanotitanium dioxide can reduce the working temperature of $\mathrm{ZnSnO}_{3}$ and improve its gas sensitivity [112,113]. Wang et al. [15] synthesized 3D flower-like micron$\mathrm{ZnSnO}_{3}$ by co-precipitation method and then decorated nano-titanium dioxide on $\mathrm{ZnSnO}_{3}$ particles via coating and sintering to fabricate UV-enhanced ethanol-sensing coatings. The working temperature was lowered from
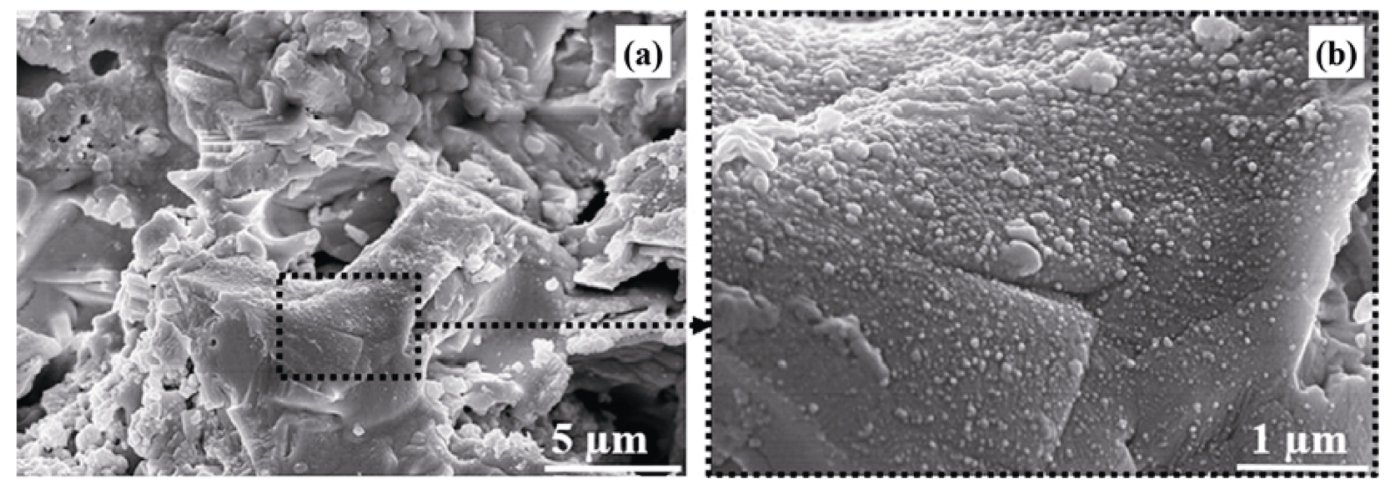

Fig. 10 SEM images of cross-sectional structure of APS + SPPS $\mathrm{WO}_{3}$ coating: (a) low magnification and (b) high magnification. Reproduced with permission from Ref. [109], (C) Elsevier B.V. 2016. 
200 to $80{ }^{\circ} \mathrm{C}$. However, it is difficult to produce coatings in mass and LPS will be a possible technology.

\section{Summary and prospect}

The construction of micro-nano structured coatings by LPS has attracted much attention. The specific functional characteristics can be obtained through structural tailoring so that the service performance of various functional coatings would be improved. The final coatings produced by different spray materials and processes can be varied greatly. Due to many applicable substrates and flexible processes, LPS micro-nano structured coatings will get more attention.

Most of the existing studies are limited to the preliminary characterization of the structure and properties of micro-nano structured coatings. The studies concerning the deposition and tailoring mechanism of micro-nano structured coatings need to be further developed to form a well-established process. That is why there is still plenty of work to be done in this field.

The plasma spray process is a rapid deposition process of a large number of particles on the substrate surface. The time interval between two adjacent particles reaching the substrate is much longer than the time required for solidification of each particle, which is also applicable to LPS. Therefore, the arrangement of the surface particles with micro-/nano-structure is adjustable. For a single sprayed particle, different shapes and sizes will be formed during flight and deposition, so it is necessary to further understand the law of a single or few particles' formations. Joshi and Sivakumar [36] studied the formation and characteristics of deposited particles in the flight process of composite spraying TBCs. As for the entire coating structure, the density, composition distribution, porosity, and geometry of coatings may be determining factors for the performance of functional coatings. After understanding the formation mechanism of the coating, micro- and nano-structure of the coating can be effectively regulated to achieve the desired performance.

In conclusion, LPS (single or hybrid) combines two kinds of materials with different scales more simply to directly change the microstructure and composition of entire coatings, ultimately improving their performance. Therefore, one of its important values is to provide a new technology for the micro-design and preparation of the micro-nano structured coating, which greatly reduces the development time and cost. With the developing of new functional coatings with micronano structures, the study of forming mechanisms, numerical simulation, and improvement of preparation technology should be the focuses of future studies.

\section{Acknowledgements}

This study is supported by the National Key R\&D Program of China (Grant No. 2017YFE0115900), the National Natural Science Foundation of China (Grant No. 51872254), and the Yangzhou City-Yangzhou University Cooperation Foundation (Grant No. YZU201801).

\section{References}

[1] Xiao YL, Huang WF, Tsui CP, et al. Ultrasonic atomization based fabrication of bio-inspired micro-nanobinary particles for superhydrophobic composite coatings with lotus/petal effect. Compos Part B: Eng 2017, 121: 92-98.

[2] Ji HC, Zeng W, Xu YZ, et al. Nanosheet-assembled hierarchical $\mathrm{WO}_{3}$ flower-like nanostructures: Hydrothermal synthesis and $\mathrm{NH}_{3}$-sensing properties. Mater Lett 2019, 250: $155-158$.

[3] Xu PY, Coyle TW, Pershin L, et al. Fabrication of micro-/nano-structured superhydrophobic ceramic coating with reversible wettability via a novel solution precursor vacuum plasma spray process. Mater Des 2018, 160: 974-984.

[4] Zhang WW, Li GR, Zhang Q, et al. Bimodal TBCs with low thermal conductivity deposited by a powdersuspension co-spray process. J Mater Sci Technol 2018, 34: 1293-1304.

[5] Yin ZB, Yuan JT, Huang CZ, et al. Friction and wear behaviors of $\mathrm{Al}_{2} \mathrm{O}_{3} / \mathrm{TiC}$ micro-nano-composite ceramic sliding against metals and hard materials. Ceram Int 2016, 42: 1982-1989.

[6] Araújo ES, Leão VNS. $\mathrm{TiO}_{2} / \mathrm{WO}_{3}$ heterogeneous structures prepared by electrospinning and sintering steps: Characterization and analysis of the impedance variation to humidity. J Adv Ceram 2019, 8: 238-246.

[7] Xu K, Zeng DW, Tian SQ, et al. Hierarchical porous $\mathrm{SnO}_{2}$ micro-rods topologically transferred from tin oxalate for fast response sensors to trace formaldehyde. Sensor Actuat B: Chem 2014, 190: 585-592.

[8] Aghasibeig M, Moreau C, Dolatabadi A, et al. Fabrication of nickel electrode coatings by combination of atmospheric and suspension plasma spray processes. Surf Coat Technol 2016, 285: 68-76.

[9] Huang J, Wang XX, Gong YF, et al. Construction of $\mathrm{WO}_{3}$ 
coatings with micro-nano hybrid structures by liquid precursor flame spray for enhanced sensing performances to sub-ppm ozone. Mater Lett 2017, 205: 106-109.

[10] Scarratt LRJ, Steiner U, Neto C. A review on the mechanical and thermodynamic robustness of superhydrophobic surfaces. Adv Colloid Interface Sci 2017, 246: 133-152.

[11] Huang QL, Li XZ, Liu T, et al. Enhanced SaOS-2 cell adhesion, proliferation and differentiation on $\mathrm{Mg}$ incorporated micro/nano-topographical $\mathrm{TiO}_{2}$ coatings. Appl Surf Sci 2018, 447: 767-776.

[12] Liu D, Ren XW, Li YS, et al. Nanowires-assembled $\mathrm{WO}_{3}$ nanomesh for fast detection of ppb-level $\mathrm{NO}_{2}$ at low temperature. $J$ Adv Ceram 2020, 9: 17-26.

[13] Yang HR, Bai XJ, Hao P, et al. A simple gas sensor based on zinc ferrite hollow spheres: Highly sensitivity, excellent selectivity and long-term stability. Sensor Actuat B: Chem 2019, 280: 34-40.

[14] Movahedi T, Norouzbeigi R. Synthesis of flower-like micro/nano $\mathrm{ZnO}$ superhydrophobic surfaces: Additive effect optimization via designed experiments. $J$ Alloys Compd 2019, 795: 483-492.

[15] Wang XY, Liu YP, Ding BN, et al. Influence of the addition of nano- $\mathrm{TiO}_{2}$ and $\mathrm{ZnO}$ on the sensing performance of micro- $\mathrm{ZnSnO}_{3}$ ethanol sensors under UV illumination. Sensor Actuat B: Chem 2018, 276: 211-221.

[16] Vardelle A, Moreau C, Themelis NJ, et al. A perspective on plasma spray technology. Plasma Chem Plasma Process 2015, 35: 491-509.

[17] Ganvir A, Curry N, Govindarajan S, et al. Characterization of thermal barrier coatings produced by various thermal Spray techniques using solid powder, suspension, and solution precursor feedstock material. Int J Appl Ceram Technol 2016, 13: 324-332.

[18] Pawlowski L. Finely grained nanometric and submicrometric coatings by thermal spraying: A review. Surf Coat Technol 2008, 202: 4318-4328.

[19] Chen L, Yang GJ. Epitaxial growth and cracking of highly tough 7YSZ splats by thermal spray technology. $J A d v$ Ceram 2018, 7: 17-29.

[20] Unabia RB, Bonebeau S, Candidato RT, et al. Preliminary study on copper-doped hydroxyapatite coatings obtained using solution precursor plasma spray process. Surf Coat Technol 2018, 353: 370-377.

[21] Candidato RT, Sokołowski P, Pawłowski L, et al. Preliminary study of hydroxyapatite coatings synthesis using solution precursor plasma spraying. Surf Coat Technol 2015, 277: 242-250.

[22] Candidato RT, Sergi R, Jouin J, et al. Advanced microstructural study of solution precursor plasma sprayed Zn doped hydroxyapatite coatings. J Eur Ceram Soc 2018, 38: 2134-2144.

[23] Zhang C, Geng X, Olivier M, et al. Solution precursor plasma-sprayed tungsten oxide coatings for nitrogen dioxide detection. Ceram Int 2014, 40: 11427-11431.
[24] Fauchais P, Etchart-Salas R, Rat V, et al. Parameters controlling liquid plasma spraying: Solutions, sols, or suspensions. J Therm Spray Tech 2008, 17: 31-59.

[25] Tarasi F, Medraj M, Dolatabadi A, et al. Enhancement of amorphous phase formation in alumina-YSZ coatings deposited by suspension plasma spray process. Surf Coat Technol 2013, 220: 191-198.

[26] Rico A, Poza P, Rodríguez J. High temperature tribological behavior of nanostructured and conventional plasma sprayed alumina-titania coatings. Vacuum 2013, 88: 149-154.

[27] Muoto CK, Jordan EH, Gell M, et al. Identification of desirable precursor properties for solution precursor plasma spray. J Therm Spray Tech 2011, 20: 802-816.

[28] Zhang SL, Li CX, Li CJ. Chemical compatibility and properties of suspension plasma-sprayed $\mathrm{SrTiO}_{3}$-based anodes for intermediate-temperature solid oxide fuel cells. J Power Sources 2014, 264: 195-205.

[29] Wang XM, Li CX, Li CJ, et al. Effect of microstructures on electrochemical behavior of $\mathrm{La}_{0.8} \mathrm{Sr}_{0.2} \mathrm{MnO}_{3}$ deposited by suspension plasma spraying. Int J Hydrog Energy 2010, 35: 3152-3158.

[30] Joulia A, Bolelli G, Gualtieri E, et al. Comparing the deposition mechanisms in suspension plasma spray (SPS) and solution precursor plasma spray (SPPS) deposition of yttria-stabilised zirconia (YSZ). J Eur Ceram Soc 2014, 34: 3925-3940.

[31] Gulyaev I, Kuzmin V, Kornienko E, et al. Microstructure formation properties of $\mathrm{ZrO}_{2}$ coating by powder, suspension and liquid precursor plasma spraying. Mater Today: Proc 2019, 11: 430-435.

[32] Fan W, Bai Y. Review of suspension and solution precursor plasma sprayed thermal barrier coatings. Ceram Int 2016, 42: 14299-14312.

[33] Ročńáková I, Slámečka K, Montufar EB, et al. Deposition of hydroxyapatite and tricalcium phosphate coatings by suspension plasma spraying: Effects of torch speed. J Eur Ceram Soc 2018, 38: 5489-5496.

[34] Sokołowski P, Kozerski S, Pawłowski L, et al. The key process parameters influencing formation of columnar microstructure in suspension plasma sprayed zirconia coatings. Surf Coat Technol 2014, 260: 97-106.

[35] Govindarajan S, Dusane RO, Joshi SV. In situ particle generation and splat formation during solution precursor plasma spraying of yttria-stabilized zirconia coatings. $J \mathrm{Am}$ Ceram Soc 2011, 94: 4191-4199.

[36] Joshi SV, Sivakumar G. Hybrid processing with powders and solutions: A novel approach to deposit composite coatings. $J$ Therm Spray Tech 2015, 24: 1166-1186.

[37] Shan YG, Wang YL, Coyle T. Analysis of deposits formation in plasma spraying with liquid precursors. Appl Therm Eng 2013, 51: 690-697.

[38] Zhang SL, Chen K, Zhang AP, et al. Effect of Fe doping on the performance of suspension plasma-sprayed $\mathrm{PrBa}_{0.5} \mathrm{~S}_{\mathrm{r} 0.5} \mathrm{Co}_{2-x} \mathrm{Fe}_{x} \mathrm{O}_{5+\delta}$ cathodes for intermediate- 
temperature solid oxide fuel cells. Ceram Int 2017, 43: 11648-11655.

[39] Ando Y, Kindole D, Noda Y, et al. Alumina and titania films deposition by APS/ASPPS dual mode thermal spray equipment using Ar added $\mathrm{N}_{2}$ working gas. Vacuum 2017, 136: 203-208.

[40] Cipri F, Marra F, Pulci G, et al. Plasma sprayed composite coatings obtained by liquid injection of secondary phases. Surf Coat Technol 2009, 203: 2116-2124.

[41] SenthiL KS, Nalluri A, Balaji N, et al. Solution precursor plasma spray process: A promising route for the fabrication of $\mathrm{Mn}-\mathrm{Co}$ oxide based protective coating for SOFC. Surf Coat Technol 2017, 324: 26-35.

[42] Xu PY, Coyle TW, Pershin L, et al. Superhydrophobic ceramic coating: Fabrication by solution precursor plasma spray and investigation of wetting behavior. $J$ Colloid Interface Sci 2018, 523: 35-44.

[43] Björklund S, Goel S, Joshi S. Function-dependent coating architectures by hybrid powder-suspension plasma spraying: Injector design, processing and concept validation. Mater Des 2018, 142: 56-65.

[44] Lohia A, Sivakumar G, Ramakrishna M, et al. Deposition of nanocomposite coatings employing a hybrid APS + SPPS technique. J Therm Spray Tech 2014, 23: 1054-1064.

[45] Cuglietta M, Kesler O. Fabrication of direct oxidation solid oxide fuel cell anodes using a novel atmospheric plasma spraying technique. ECS Trans 2019, 35: 1781-1790.

[46] Ajay A, Raja VS, Sivakumar G, et al. Hot corrosion behavior of solution precursor and atmospheric plasma sprayed thermal barrier coatings. Corros Sci 2015, 98: 271-279.

[47] Murray JW, Leva A, Joshi S, et al. Microstructure and wear behaviour of powder and suspension hybrid $\mathrm{Al}_{2} \mathrm{O}_{3}-\mathrm{YSZ}$ coatings. Ceram Int 2018, 44: 8498-8504.

[48] Skoog A, Murphy J, Tomlinson T. Method for applying a plasma sprayed coating using liquid injection. U.S. patent application, 20060222 777, Oct. 2006.

[49] Mohanty PS, Moroz NA. In-situ plasma/laser hybrid scheme. U.S. patent, 8294 060, Oct. 2012.

[50] Qu JF, Wang W, Chen YB, et al. Stable direct-methane solid oxide fuel cells with calcium-oxide-modified nickel-based anodes operating at reduced temperatures. Appl Energy 2016, 164: 563-571.

[51] Cuglietta M, Kesler O. Relationship between particle and plasma properties and coating characteristics of Samariadoped ceria prepared by atmospheric plasma spraying for use in solid oxide fuel cells. $J$ Therm Spray Tech 2012, 21: 448-460.

[52] Cuglietta MJ. The fabrication of direct oxidation solid oxide fuel cell anodes using atmospheric plasma spraying. Ph.D. Thesis. Toronto, Canada: University of Toronto, 2013.

[53] Yin K, Dong XR, Zhang F, et al. Superamphiphobic miniature boat fabricated by laser micromachining. Appl Phys Lett 2017, 110: 121909.

[54] Tulcidas AV, Bayón R, Igartua A, et al. Friction reduction on recent non-releasing biocidal coatings by a newly designed friction test rig. Tribol Int 2015, 91:140-150.

[55] Zhai MJ, Gong YF, Chen XY, et al. Mass-producible hydrophobic perfluoroalkoxy/nano-silver coatings by suspension flame spraying for antifouling and drag reduction applications. Surf Coat Technol 2017, 328: $115-120$.

[56] Sharifi N, Pugh M, Moreau C, et al. Developing hydrophobic and superhydrophobic $\mathrm{TiO}_{2}$ coatings by plasma spraying. Surf Coat Technol 2016, 289: 29-36.

[57] Li ZF, Zheng YJ, Zhao J, et al. Wettability of atmospheric plasma sprayed $\mathrm{Fe}, \mathrm{Ni}, \mathrm{Cr}$ and their mixture coatings. $J$ Therm Spray Tech 2012, 21: 255-262.

[58] Xu R, Zhang LX, Li MW, et al. Ultrathin $\mathrm{SnO}_{2}$ nanosheets with dominant high-energy $\{001\}$ facets for low temperature formaldehyde gas sensor. Sensor Actuat B: Chem 2019, 289: 186-194.

[59] You JJ, Chen X, Zheng BB, et al. Suspension plasmasprayed $\mathrm{ZnFe}_{2} \mathrm{O}_{4}$ nanostructured coatings for ppm-level acetone detection. $J$ Therm Spray Tech 2017, 26: 728-734.

[60] Zhang C, Geng X, Li H, et al. Microstructure and gas sensing properties of solution precursor plasma-sprayed zinc oxide coatings. Mater Res Bull 2015, 63: 67-71.

[61] Geng X, You JJ, Zhang C. Microstructure and sensing properties of $\mathrm{CdS}-\mathrm{ZnO}_{1-x}$ coatings deposited by liquid plasma spray and treated with hydrogen peroxide solution for nitrogen dioxide detection at room temperature. J Alloys Compd 2016, 687: 286-293.

[62] Heimann RB. Plasma-sprayed hydroxylapatite coatings as biocompatible intermediaries between inorganic implant surfaces and living tissue. $J$ Therm Spray Tech 2018, 27: 1212-1237.

[63] Imrie FE, Skakle JM, Gibson IR. Preparation of copperdoped hydroxyapatite with varying $x$ in the composition $\mathrm{Ca}_{10}\left(\mathrm{PO}_{4}\right)_{6} \mathrm{Cu}_{x} \mathrm{O}_{y} \mathrm{H}_{z}$. Bioceram Dev Appl 2013, S1: 005.

[64] Huang Y, Zhang XJ, Mao HH, et al. Osteoblastic cell responses and antibacterial efficacy of $\mathrm{Cu} / \mathrm{Zn}$ co-substituted hydroxyapatite coatings on pure titanium using electrodeposition method. RSC Adv 2015, 5: 1707617086.

[65] Zalnezhad E, Hamouda AMS, Faraji G, et al. $\mathrm{TiO}_{2}$ nanotube coating on stainless steel 304 for biomedical applications. Ceram Int 2015, 41: 2785-2793.

[66] Zhao XB, Wang GC, Zheng H, et al. Delicate refinement of surface nanotopography by adjusting $\mathrm{TiO}_{2}$ coating chemical composition for enhanced interfacial biocompatibility. ACS Appl Mater Interfaces 2013, 5: 8203-8209.

[67] Kozerski S, Toma FL, Pawlowski L, et al. Suspension plasma sprayed $\mathrm{TiO}_{2}$ coatings using different injectors and their photocatalytic properties. Surf Coat Technol 2010, 205: 980-986.

[68] Zhang WX, Gu JP, Zhang C, et al. Preparation of titania coating by induction suspension plasma spraying for biomedical application. Surf Coat Technol 2019, 358: $511-520$ 
[69] Yao ZP, Zhang YJ, He YQ, et al. Synthesis of hierarchical dendritic micro-nano structure $\mathrm{ZnFe}_{2} \mathrm{O}_{4}$ and photocatalytic activities for water splitting. Chin J Chem Eng 2016, 24: 1112-1116.

[70] Zhu K, Luo Q, Chen Q, et al. Dramatically enhanced photocatalytic hydrogen production over pompoms-like cadmium molybdate nano-micro hybrids modulated by copper ions. Int J Hydrog Energy 2019, 44: 8273-8278.

[71] Toma FL, Bertrand G, Chwa SO, et al. Comparative study on the photocatalytic decomposition of nitrogen oxides using $\mathrm{TiO}_{2}$ coatings prepared by conventional plasma spraying and suspension plasma spraying. Surf Coat Technol 2006, 200: 5855-5862.

[72] Yu ZX, Moussa H, Liu MM, et al. Tunable morphologies of $\mathrm{ZnO}$ films via the solution precursor plasma spray process for improved photocatalytic degradation performance. Appl Surf Sci 2018, 455: 970-979.

[73] Zhai MJ, Liu Y, Huang J, et al. Efficient suspension plasma spray fabrication of black titanium dioxide coatings with visible light absorption performances. Ceram Int 2019, 45: 930-935.

[74] Wang CH, Wang Y, Fan S, et al. Optimized functionally graded $\mathrm{La}_{2} \mathrm{Zr}_{2} \mathrm{O}_{7} / 8 \mathrm{YSZ}$ thermal barrier coatings fabricated by suspension plasma spraying. $J$ Alloys Compd 2015, 649: 1182-1190.

[75] Stern AG. A new sustainable hydrogen clean energy paradigm. Int J Hydrog Energy 2018, 43: 4244-4255.

[76] Hui R, Wang ZW, Kesler O, et al. Thermal plasma spraying for SOFCs: Applications, potential advantages, and challenges. J Power Sources 2007, 170: 308-323.

[77] Aghasibeig M, Mousavi M, Ben Ettouill F, et al. Electrocatalytically active nickel-based electrode coatings formed by atmospheric and suspension plasma spraying. $J$ Therm Spray Tech 2014, 23: 220-226.

[78] Aghasibeig M, Dolatabadi A, Wuthrich R, et al. Threedimensional electrode coatings for hydrogen production manufactured by combined atmospheric and suspension plasma spray. Surf Coat Technol 2016, 291: 348-355.

[79] Cho J, Li J, Shang Z, et al. Comparison of temperature dependent deformation mechanisms of 8YSZ thermal barrier coatings prepared by air-plasma-spray and D-Gun thermal spray: An in situ study. J Eur Ceram Soc 2019, 39: 3120-3128.

[80] Basnet B, Sarkar N, Park JG, et al. $\mathrm{Al}_{2} \mathrm{O}_{3}-\mathrm{TiO}_{2} / \mathrm{ZrO}_{2}-\mathrm{SiO}_{2}$ based porous ceramics from particle-stabilized wet foam. $J$ Adv Ceram 2017, 6: 129-138.

[81] Krivoshapkina EF, Krivoshapkin PV, Vedyagin AA. Synthesis of $\mathrm{Al}_{2} \mathrm{O}_{3}-\mathrm{SiO}_{2}-\mathrm{MgO}$ ceramics with hierarchical porous structure. $J A d v$ Ceram 2017, 6: 11-19.

[82] Zhang WW, Li GR, Zhang Q, et al. Multiscale pores in TBCs for lower thermal conductivity. J Therm Spray Tech 2017, 26: 1183-1197.

[83] Joshi SV, Sivakumar G, Raghuveer T, et al. Hybrid plasma-sprayed thermal barrier coatings using powder and solution precursor feedstock. J Therm Spray Tech 2014, 23 :
616-624.

[84] Vaßen R, Jarligo MO, Steinke T, et al. Overview on advanced thermal barrier coatings. Surf Coat Technol 2010, 205: 938-942.

[85] Kumar R, Cietek D, Jiang C, et al. Influence of microstructure on the durability of gadolinium zirconate thermal barrier coatings using APS \& SPPS processes. Surf Coat Technol 2018, 337: 117-125.

[86] Ahmadi MS, Shoja-Razavi R, Valefi Z, et al. Evaluation of hot corrosion behavior of plasma sprayed and laser glazed $\mathrm{YSZ}-\mathrm{Al}_{2} \mathrm{O}_{3}$ thermal barrier composite. Opt Laser Technol 2019, 111: 687-695.

[87] Sivakumar G, Banerjee S, Raja VS, et al. Hot corrosion behavior of plasma sprayed powder-solution precursor hybrid thermal barrier coatings. Surf Coat Technol 2018, 349: 452-461.

[88] Lima RS, Kucuk A, Berndt CC. Bimodal distribution of mechanical properties on plasma sprayed nanostructured partially stabilized zirconia. Mater Sci Eng: A 2002, 327: 224-232.

[89] Lima RS, Marple BR. Nanostructured YSZ thermal barrier coatings engineered to counteract sintering effects. Mater Sci Eng: A 2008, 485: 182-193.

[90] Gao LH, Guo HB, Gong SK, et al. Plasma-sprayed $\mathrm{La}_{2} \mathrm{Ce}_{2} \mathrm{O}_{7}$ thermal barrier coatings against calciummagnesium-alumina-silicate penetration. J Eur Ceram Soc 2014, 34: 2553-2561.

[91] Praveen K, Sravani N, Alroy RJ, et al. Hot corrosion behaviour of atmospheric and solution precursor plasma sprayed $\left(\mathrm{La}_{0.9} \mathrm{Gd}_{0.1}\right)_{2} \mathrm{Ce}_{2} \mathrm{O}_{7}$ coatings in sulfate and vanadate environments. J Eur Ceram Soc 2019, 39: 4233-4244.

[92] Hou HD, Veilleux J, Gitzhofer F, et al. Hybrid suspension/solution precursor plasma spraying of a complex $\mathrm{Ba}\left(\mathrm{Mg}_{1 / 3} \mathrm{Ta}_{2 / 3}\right) \mathrm{O}_{3}$ perovskite: Effects of processing parameters and precursor chemistry on phase formation and decomposition. J Therm Spray Tech 2019, 28: 12-26.

[93] Jinga C, Andronescu E, Jinga S, et al. Synthesis and characterization of doped $\mathrm{Ba}\left(\mathrm{Mg}_{1 / 3} \mathrm{Ta}_{2 / 3}\right) \mathrm{O}_{3}$ ceramics. $J$ Optoelectron Adv M 2010, 12: 282-287.

[94] Mohanty PS, Roche AD, Guduru RK, et al. Ultrafine particulate dispersed high-temperature coatings by hybrid spray process. $J$ Therm Spray Tech 2010, 19: 484-494.

[95] An YL, Li SJ, Hou GL, et al. Mechanical and tribological properties of nano/micro composite alumina coatings fabricated by atmospheric plasma spraying. Ceram Int 2017, 43: 5319-5328.

[96] Bolelli G, Candeli A, Lusvarghi L, et al. Tribology of $\mathrm{NiCrAlY}+\mathrm{Al}_{2} \mathrm{O}_{3}$ composite coatings by plasma spraying with hybrid feeding of dry powder+suspension. Wear 2015, 344-345: 69-85.

[97] Bolelli G, Candeli A, Lusvarghi L, et al. "Hybrid" plasma spraying of $\mathrm{NiCrAlY}+\mathrm{Al}_{2} \mathrm{O}_{3}+\mathrm{h}-\mathrm{BN}$ composite coatings for sliding wear applications. Wear 2017, 378: 68-81.

[98] Du LZ, Huang CB, Zhang WG, et al. Preparation and 
wear performance of $\mathrm{NiCr} / \mathrm{Cr}_{3} \mathrm{C}_{2}-\mathrm{NiCr} / \mathrm{hBN}$ plasma sprayed composite coating. Surf Coat Technol 2011, 205: 3722-3728.

[99] Kiilakoski J, Puranen J, Heinonen E, et al. Characterization of powder-precursor HVOF-sprayed $\mathrm{Al}_{2} \mathrm{O}_{3}-\mathrm{YSZ} / \mathrm{ZrO}_{2}$ coatings. $J$ Therm Spray Tech 2019, 28: 98-107.

[100] Lupan O, Ursaki VV, Chai G, et al. Selective hydrogen gas nanosensor using individual $\mathrm{ZnO}$ nanowire with fast response at room temperature. Sensor Actuat B: Chem 2010, 144: 56-66.

[101] Kim JH, Mirzaei A, Kim HW, et al. Pd functionalization on $\mathrm{ZnO}$ nanowires for enhanced sensitivity and selectivity to hydrogen gas. Sensor Actuat B: Chem 2019, 297: 126693.

[102] Hoppe M, Lupan O, Postica $\mathrm{V}$, et al. $\mathrm{ZnAl}_{2} \mathrm{O}_{4}$ functionalized zinc oxide microstructures for highly selective hydrogen gas sensing applications. Phys Status Solidi a 2018, 215: 1700772.

[103] Zhang JJ, Guo EJ, Wang LP, et al. Effect of annealing treatment on morphologies and gas sensing properties of $\mathrm{ZnO}$ nanorods. Trans Nonferrous Met Soc China 2014, 24: 736-742.

[104] Dey A. Semiconductor metal oxide gas sensors: A review. Mater Sci Eng: B 2018, 229: 206-217.

[105] Chu SS, Yang C, Su XT. Synthesis of NiO hollow nanospheres via Kirkendall effect and their enhanced gas sensing performance. Appl Surf Sci 2019, 492: 82-88.

[106] Meng D, Yamazaki T, Kikuta T. Preparation and gas sensing properties of undoped and Pd-doped $\mathrm{TiO}_{2}$ nanowires. Sensor Actuat B: Chem 2014, 190: 838-843.

[107] Kaur M, Kailasaganapathi S, Ramgir N, et al. Gas dependent sensing mechanism in $\mathrm{ZnO}$ nanobelt sensor. Appl Surf Sci 2017, 394: 258-266.

[108] Waitz T, Becker B, Wagner T, et al. Ordered nanoporous $\mathrm{SnO}_{2}$ gas sensors with high thermal stability. Sensor
Actuat B: Chem 2010, 150: 788-793.

[109] Zhang C, Wang J, Geng X. Tungsten oxide coatings deposited by plasma spray using powder and solution precursor for detection of nitrogen dioxide gas. $J$ Alloys Compd 2016, 668: 128-136.

[110] Chen C, Li GZ, Li JH, et al. One-step synthesis of 3D flower-like $\mathrm{Zn}_{2} \mathrm{SnO}_{4}$ hierarchical nanostructures and their gas sensing properties. Ceram Int 2015, 41: 1857-1862.

[111] Kheel H, Sun GJ, Lee JK, et al. Enhanced $\mathrm{H}_{2} \mathrm{~S}$ sensing performance of $\mathrm{TiO}_{2}$-decorated $\alpha-\mathrm{Fe}_{2} \mathrm{O}_{3}$ nanorod sensors. Ceram Int 2016, 42: 18597-18604.

[112] Wang XY, Li MX, Ding BN, et al. UV-enhanced ethanol-sensing properties of $\mathrm{TiO}_{2}$-decorated $\mathrm{ZnSnO}_{3}$ hollow microcubes at low temperature. J Mater Sci: Mater Electron 2017, 28: 12399-12407.

[113] Wang XY, Ding BN, Liu YP, et al. Synthesis of 3D flower-like $\mathrm{ZnSnO}_{3}$ and improvement of ethanol-sensing properties at room temperature based on nano- $\mathrm{TiO}_{2}$ decoration and UV radiation. Sensor Actuat B: Chem 2018, 264: 119-127.

Open Access This article is licensed under a Creative Commons Attribution 4.0 International License, which permits use, sharing, adaptation, distribution and reproduction in any medium or format, as long as you give appropriate credit to the original author(s) and the source, provide a link to the Creative Commons licence, and indicate if changes were made.

The images or other third party material in this article are included in the article's Creative Commons licence, unless indicated otherwise in a credit line to the material. If material is not included in the article's Creative Commons licence and your intended use is not permitted by statutory regulation or exceeds the permitted use, you will need to obtain permission directly from the copyright holder.

To view a copy of this licence, visit http://creativecommons. org/licenses/by/4.0/. 